\title{
Piaget's Theory and Stages of Cognitive Development- An Overview
}

Rabindran $^{1 *}$, Darshini Madanagopal ${ }^{2}$

Consultant, Neonatologist, Billroth Hospital, Chennai, India

${ }^{2}$ Assistant Professor, Department of Psychology, Institute of Distance Education, University of Madras, Chennai, India

DOI: $10.36347 /$ sjams.2020.v08i09.034

| Received: 15.09.2020 | Accepted: 23.09.2020 | Published: 25.09.2020

*Corresponding author: Rabindran

\section{Abstract}

Cognitive development is the capability of knowing, comprehending or understanding. Piaget studied about how children develop ability to think logically and scientifically. According to Piaget assimilation and accommodation are important for effective learning. Piaget made some assumptions that children build their knowledge based on experiences, they learn without influence from others, and by nature, they are motivated to learn. Piaget stated that development of cognition occurred through distinct stages which happen in the same order. Piaget's stages include Sensorimotor stage (birth to 2 years), Preoperational stage (2 to 7 years), Concrete operational stage (7 to 11 years) and Formal operational stage (11 years and beyond). Cognitive development at sensorimotor stage is characterised by goal directed behaviour, object permanence, mental representation, cause and effect relationship and coordinated space. Sensorimotor stage is further subdivided into six substages. Every substage is associated with newer skill development. Cognitive development at preoperational stage is characterised by Transductive reasoning, Animism, Artificialism, Egocentrism, Symbolic Functioning, Centration, Irreversibility, Curiosity and Seriation. Key behaviours during preoperational stage include imitation, symbolic play, drawing, mental imagery and verbal evocation of events. Cognitive development at concrete operational stage is characterised by Logical thinking, Decentration, Reversibility, Cause and Effect relationship, Classification, Transitivity and Elimination of Egocentrism. Cognitive development at formal operational stage is characterised by Abstract thinking, Deductive reasoning, Problem solving, Hypothetical thinking, Adolescent Ego-centrism, Imaginary Audience and Personal fable. Basic components of piaget's cognitive theory include Stages, Schemas and Adaptations. Intellectual development is not a quantitative process, but a qualitative change.

Keywords: Piaget's theory, Cognitive development, Schema.

Copyright @ 2020: This is an open-access article distributed under the terms of the Creative Commons Attribution license which permits unrestricted use, distribution, and reproduction in any medium for non-commercial use (NonCommercial, or CC-BY-NC) provided the original author and source are credited.

\section{INTRODUCTION}

Development is an improvement in functional efficiency. Cognition involves thinking and memory and it is a means to perceive, comprehend, and conceive or simply to know. Cognitive development means the capability of knowing, comprehending or understanding. Cognitive development is facilitated by maturity and environmental interaction [1].

\section{Piaget's Concept}

Piaget studied about how children develop ability to think logically and scientifically. According to Piaget assimilation and accommodation are important for effective learning. Assimilation is adjusting new experiences to fit prior concepts and accommodation is adjusting concepts to fit new experiences. The two processes leads to short-term learning as well as longterm developmental change, which is the main focus of Piaget's cognitive theory. 


\section{Basic Components of Piaget's Cognitive Theory}

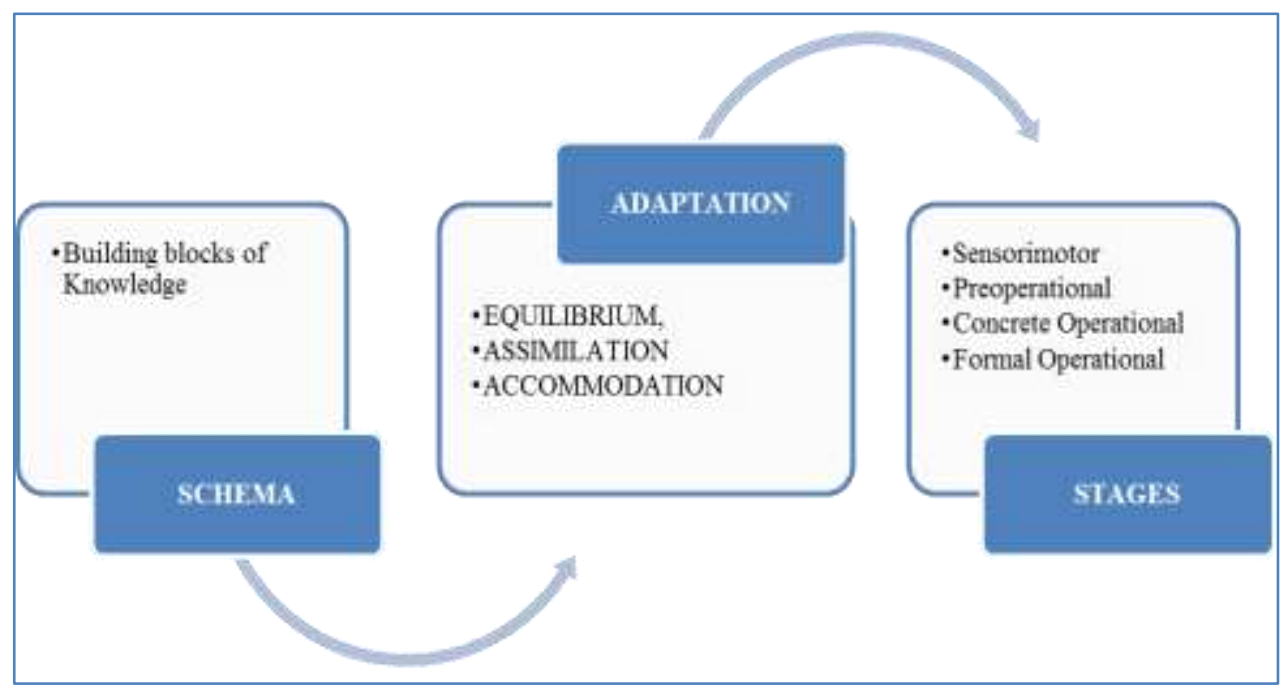

While developing the cognitive theory, Piaget made some assumptions about children which include 1) Based on their experiences, children build their knowledge, 2) Children learn things without influence from others, 3) By nature, children are motivated to learn. The four basic elements in cognitive development are Maturation, Experience, Social transmission and Equilibrium [2].

\section{Stages of Cognitive Development}

Piaget stated that development of cognition occurred through distinct stages [3]. The stages have certain characteristics mimicking staircase model of development. The stages happen in the same order and no stage is skipped [4]. Every stage is a transformation of antecedent stage [5]. Subsequent stage incorporates the earlier stages into itself. Piaget's stages are agespecific and include goals that children are expected to achieve in a stage [6].

\begin{tabular}{|c|c|}
\hline \multicolumn{2}{|r|}{ SENSORIMOTOR } \\
\hline Object permanence & Motor activity without use of symbols. \\
\hline \multicolumn{2}{|r|}{ PREOPERATIONAL } \\
\hline Symbolic thought & Development of language, memory, and imagination \\
\hline \multicolumn{2}{|r|}{ CONCRETE OPERATIONAL } \\
\hline Operational thought & Logical and methodical manipulation of symbols \\
\hline \multicolumn{2}{|r|}{ FORMAL OPBRATIONAL. } \\
\hline Abstract concepts & Use of symbols to relate to abstract concepts. \\
\hline
\end{tabular}

\section{Sensorimotor Stage: Birth to 2 Years}

During this stage, infants think using their senses and motor actions [7]. They learn about the world by touching, looking, listening or biting things. These help children to develop simple concepts of objects [8]. This stage is characterised by motor activity without use of symbols. Trial and error method is the major basis of learning. Cognitive development at this stage is characterised by goal directed behaviour, object permanence concept, mental representation, cause and effect relationship and coordinated space.
Goal directed behaviour: During Sensorimotor stage reflex action ends. This stage is marked by beginning of directed behaviour. In infancy there are 3 primitive reflexes like sucking, following objects with eyes and palmer grasp. However this reflexive action changes to voluntary goal directed action like intentional grasping around six weeks of life.

Object permanence concept: During Sensorimotor stage child develops the awareness that an object continues to exist even when it is hidden from view [9]. 
Mental representation: The child develops the ability to keep mental picture of an event even beyond immediate experience. For example a child may begin a tantrum after seeing another child doing it some time ago. This is known as deferred imitation.

Cause and effect relationship: Child learns the concept of object casuality. He / She develops that there is a cause and effect association. A child may make different sounds to get the attention from caregivers.
Coordinated space: During Sensorimotor stage, child develops concept that coordination occurs among different objects and between objects and the body. Now child starts to believe that a rattle when shaken makes sounds. The concept that self is not an extension with surrounding and the existence of a boundary between self and the surrounding is established during this stage.

Sensorimotor stage is further subdivided into six substages. Every substage is associated with development of a new skill.

\begin{tabular}{|c|c|}
\hline \multicolumn{2}{|r|}{ REFLENES } \\
\hline Upto 1 month & Understanding enviroument through reflexes \\
\hline \multicolumn{2}{|r|}{ PRIMARY CIRCUL AR REACTIONS } \\
\hline \multicolumn{2}{|r|}{ New schemas and sensations are combined } \\
\hline \multicolumn{2}{|r|}{ SECONDARY CIRCULAR REACTIONS: } \\
\hline 4.8 months & Awareness that their actions influence their environment \\
\hline & COORDINATION OF REACTIONS \\
\hline 8- 12 months & Exploring environment and imitation. \\
\hline & \\
\hline \multicolumn{2}{|r|}{ TERTIARY CIRCULAR REACIIONS: } \\
\hline $12-18$ months & Experiment new behavior. \\
\hline \multicolumn{2}{|r|}{ EARLY REPRESENTATIONAL THOEGHI } \\
\hline 18-24 months & Recognizing symbols that represent objects. \\
\hline
\end{tabular}

\section{Preoperational Stage: 2 to 7 years}

Cognitive development at this stage is characterised by Transductive reasoning, Animism, Artificialism Egocentrism, Symbolic Functioning, Centration, Irreversibility, Curiosity and Seriation.

Transductive reasoning: Child starts to associate two separate events which are otherwise unrelated. They fail to understand cause and effect relationship.

Animism: Child believes that inanimate objects have life and are capable of actions

Artificialism: Child believes that environmental objects are controlled by people.
Egocentrism: During this stage, child believes that others see, feel and think exactly the same as him / herself [10].

Symbolic functioning: Child develops the ability to make use of symbols in communication.

Centration: Child develops the ability to focus attention on only one aspect of a situation at a time.

Irreversibility: A child cannot reverse in mind what he/ she does or knows.

Curiosity: Child begins to ask a lot of questions because of curiosity.

Seriation: Child does not have the ability to classify things into categories [11]. 


\section{Key Behaviors during Preoperational Stage}

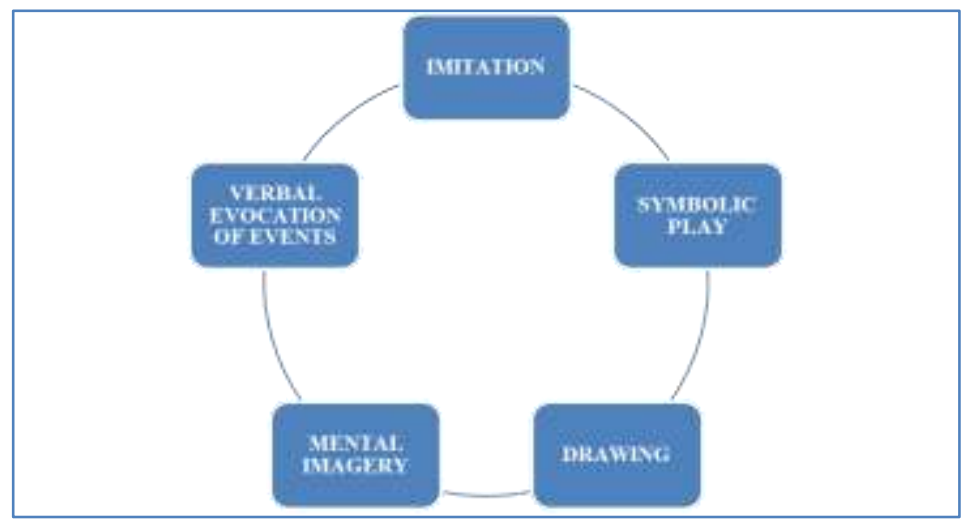

Child develops the ability to think on two levels simultaneously- imaginative and realistic [12]. Important behaviours which develop during this period are

IMITATION Mimicing someone's behaviour SYMBOLIC PLAY Using objects as symbols. DRAWING Involves both imitation and symbolic play. MENTAL IMAGERY Imagining many objects in minds.

VERBAL EVOCATION OF EVENTS Using language to describe events, people or objects.

\section{Concrete Operational Stage: 7 to 11 years}

Children at this stage apply logical thinking [13]. Cognitive development at this stage is characterised by Logical thinking, Decentration, Reversibility, Cause and Effect relationship, Classification, Transitivity and Elimination of Egocentrism [14].

Logical thinking: Illogical thinking like Animism, Artificialism, Irreversibility are replaced by logical, concrete thinking process [15].

Decentration: Now child develops the ability to focus attention on many aspects of a situation simultaneously [16].

Reversibility: Child can reverse the thought in their minds. Once they know the route from home to school, they can picturise the reverse route from school to home.

Cause and Effect relationship: Children develop the concept that there is a cause for some event. At this stage they understand cause of rain is because of clouds in the sky.

Classification: Child is able to classify things based of their properties. Child develops the ability to arrange things according to some order (from small to large, thin to thick, light to heavy) [17].
Transitivity: Child arrives to some conclusions by combining relations logically.

Elimination of Egocentrism: Child starts to view things from another's perspectives as well.

Formal Operational Stage: Age 11 and Beyond Cognitive development at this stage is characterised by Abstract thinking, Deductive reasoning, Problem solving, Hypothetical thinking, Adolescent Ego-centrism, Imaginary Audience and Personal fable [18]. Everyone does not reach the stage of formal operations.

\section{Abstract thinking}

Children begin to imagine and predict the possible outcome of actions and develop long term planning [20].

\section{Deductive Reasoning}

Child develops the ability to use a general rule to determine specific outcomes. For example, if $\mathrm{A}=\mathrm{B}$ and $B=C$, then $A=C[21]$.

Problem Solving: Child is now able to solve a problem in a logical and methodical way [22].

Hypothetical Thinking: Child can guess about the possible outcomes [23].

Adolescent Ego-Centrism: Child at this stage has high self-consciousness. He / She believes that others are interested in him / her. They develop concept of imaginary audience (Belief that others are watching them) and personal fable (he /she is the centre of attention) [24].

As already discussed basic components of piaget's cognitive theory include Stages, Schemas and Adaptations. Now we will discuss on schemas.

\section{Schemas}

Schemas are basic building blocks of cognitive models [25]. It is a mental representation of the world. 
We use these to understand and respond to situations. We store these representations mentally and apply them when needed [26]. An example is a person buying a meal in a restaurant. The schema is stored form of behaviour including seeing the menu card, giving order for food, eating food and giving money for the bill. Piaget has proposed the importance of schemas in cognitive development.

\section{Adaptations \\ According to Paiget's Cognitive theory, there are 3 components in adaptation namely Equilibration, Assimilation and Accommodation. Adaptation is inborn tendency to adjust more attuned to environmental conditions [27].}

Equilibration is force that moves development along. The progress in cognitive development is not steady but there are leaps and bounds [28]. When a child's schemas can deal with most new information Equilibrium is attained [29].

Assimilation is using an existing schema to deal with a new situation. It is incorporating into an existing schema [30].

Accommodation occurs when existing schema doesn't work, and needs to be changed to deal with new situation. It is modification of a prior schema.

\section{Relevance of piaget's theory in clinical child development \\ Educational implications of piaget's theory \\ Piaget's theory suggested developmentally} appropriate education where education with environment, curriculum, materials and instruction are in consistency with student's physical and cognitive abilities [31]. Children learn about the world by taking part in various activities, So he emphasized the importance of Discovery learning - freedom to explore and discover knowledge

Problem solving - content should be taught in the form of problems.

Projects- using projects as a means to learn. Activity based method should be used and teacher is considered as facilitator.

Stage Based teaching: identifying cognitive level and teaching students accordingly.

At sensorimotor stage, when senses and motor skills are used to explore the environment - verbal interactions and object rich environment is beneficial. During pre-operational stage, when logical reasoning has not formed, the teacher should use schemas necessary for logical thought. In concrete operational stage, interactions with concrete materials are provided, since abstract thinking has developed. Finally, during formal operational stage abstract concepts can be taught. Piaget's work is a rationale for play as an effective way for learning and development among children [32]. Piaget's model assumes that learning takes place from inside out, based on innate developmental stages [33]. School should provide a good stimulating environment for proper development of children's mental abilities. Opportunity should be given for development of creative abilities through music, dance, art and crafts.

\section{CONCLUSION}

Piaget's cognitive theory can be incorporated into any education program. Props and other aids should be used to support learning. It is important to keep things simple and short. Intellectual development is not a quantitative process, i.e. not adding information to existing knowledge. Instead, development is a qualitative change, gradually processing information and changing existing understanding accordingly.

\section{REFERENCE}

1. Papalia DE, Olds SW, Feldman RD. A child's world: Infancy through adolescence. New York: McGraw-Hill; 1990 Jan.

2. Huitt W, Hummel J. Piaget's theory of cognitive development. Educational psychology interactive. 2003;3(2):1-5.

3. Piaget J. Piaget's theory. In Piaget and his school. Springer, Berlin, Heidelberg. 1976; 11-23

4. Eggen PD, Kauchak DP. Educational psychology: windows on classrooms 5 th edth ed.

5. Berk LE. Child development (4th ed.). Needham Heights,MA: Allyn \& Bacon;1997.

6. Hetherington EM, Parke RD, Locke VO. Child psychology: A contemporary viewpoint. McGrawHill; 1999.

7. Meyer WJ, Dusek JB. Child Psychology Developmental perspective Syracuse University: DC Health and company.

8. Donald DR, Lazarus S, Lolwana P. Educational psychology in social context. Oxford University Press; 2006.

9. Baillargeon R. Object permanence in $3 \frac{1}{2}$-and $4 \frac{1}{2} 2_{-}^{-}$ month-old infants. Developmental psychology. 1987 Sep; 23(5):655.

10. Newcombe NS. Cognitive development: changing views of cognitive change. Wiley Interdisciplinary Reviews: Cognitive Science. 2013 Sep;4(5):47991.

11. Thurstone LL. "Attitudes Can Be Measured." American Journal of Sociology. 1928; 33: 529-554.

12. Paley VG. A child's work: The importance of fantasy play. University of Chicago Press; 2009:15.

13. Miller PH. Piaget's Theory: Past, Present, and Future. The Wiley-Blackwell Handbook of Childhood Cognitive Development, Second edition. 2010;649-672. 
14. Piaget J. The psychology of intelligence. Oxford, UK: Routledge; 2001.

15. Singer DG, Revenson TA. A Piaget primer: How a child thinks. International Universities Press, Inc., 59 Boston Post Road, Madison, CT. 19997; 064431524.

16. Woolfolk A. Educational psychology. Active learning edition (2nd ed.). Boston, MA: Allyn \& Bacon; 2008.

17. Piaget J, Grize JB, Szeminska A, Bang V. Epistemology and psychology of functions. Springer Science \& Business Media; 1977.

18. Wilks T, Gerber RJ, Erdie-Lalena C. Developmental milestones: cognitive development. Pediatrics in review. 2010 Sep;31(9):364.

19. Case R, Okamoto Y, Griffin S, McKeough A, Bleiker C, Henderson B, Stephenson KM, Siegler RS, Keating DP. The role of central conceptual structures in the development of children's thought. Monographs of the society for research in child development. 1996 Jan 1:i-295.

20. Lehman DR, Nisbett RE. A longitudinal study of the effects of undergraduate training on reasoning. Developmental Psychology. 1990 Nov;26(6):952.

21. Anderson JR, Crawford J. Cognitive psychology and its implications. San Francisco: wh freeman; $1980 \mathrm{Jul}$.

22. Miller SM. Transmediating with multimodal literacies: Adolescents' literature learning through DV Composing. 60th Yearbook of the Literacy Research Association. 2011:389-406.
23. Evans RI. Jean Piaget: The man and his ideas. EP Dutton; 1973.

24. Elkind D. Child development in educational settings. Educational Psychologist. 1976 Jan 1;12(1):49-58.

25. Piaget J. Piaget's Theory, Handbook of Child Psychology, 1. New York: Wiley. 1983.

26. Wadsworth BJ. Piaget's theory of cognitive and affective development: Foundations of constructivism. Longman Publishing; 1996.

27. Cherry K. Piaget's stages of cognitive development. About. com. 2015.

28. Bukatko D, Daehler MW. Child development: A thematic approach. Nelson Education; 2012 Dec 20.

29. Lavatelli CS. Piaget's theory applied to an early childhood curriculum. American Science and Engineering; 1973.

30. Siegler RS, DeLoache JS, Eisenberg N. How children develop. Macmillan; 2003.

31. Mwamwenda TS. Educational psychology: an African perspective. Sandton, South Africa, Heinemann; 2004.

32. Neaum S. Child development for early year's students and practitioners. Learning Matters; 2019 Feb 25.

33. Rose D. Democratising the classroom: literacy pedagogy for the new generation. Journal of education. 2005 Jan 1;37(1):131-68. 